\title{
Influence of horizon elevation on the sea-finding behaviour of hatchling flatback turtles exposed to artificial light glow
}

\author{
Kellie Pendoley, Ruth L. Kamrowski* \\ Pendoley Environmental Pty Ltd, 12A Pitt Way, Booragoon, Western Australia 6154, Australia
}

\begin{abstract}
Marine turtles are threatened globally by increasing coastal development. In particular, increased artificial lighting at the nesting beach has the potential to disrupt turtle breeding success. Few published data exist regarding the behaviour of the flatback turtle Natator depressus, a species endemic to Australia, in response to artificial light. Given the ongoing industrialisation of the Australian coastline, this study is a timely investigation into the orientation of flatback hatchlings exposed to light glow produced by lighting typically used in industrial settings. We recorded the orientation of hatchlings at the nesting beach on Barrow Island, Western Australia, exposed to 3 types of standard lighting — high-pressure sodium vapour (HPS), metal halide (MH), and fluorescent white (FW) - at 3 different intensities. The light array was positioned either behind a high dune (producing a high, dark silhouette; $16^{\circ}$ elevation), or in a low creek bed (producing a low silhouette and bright horizon; $2^{\circ}$ elevation). At medium and high light intensities of all 3 light types, hatchlings were significantly less ocean-oriented when exposed to light at $2^{\circ}$ elevation compared to $16^{\circ}$ elevation. This difference remained with glow from low-intensity $\mathrm{MH}$ light; however, there was no significant difference in orientation of hatchlings exposed to lowintensity HPS and FW light glow at either elevation. Our study emphasises the importance of horizon elevation cues in hatchling sea-finding. Since all species of marine turtles show similar seafinding behaviour, our results have important implications for management of lighting adjacent to turtle nesting beaches in Australia and elsewhere, as coastal development continues.
\end{abstract}

KEY WORDS: Hatchling orientation - Artificial lighting · Horizon elevation - Marine turtle Conservation management $\cdot$ Elevation $\cdot$ Industry $\cdot$ Coastal development

Resale or republication not permitted without written consent of the publisher

\section{INTRODUCTION}

Global increases in artificial lighting threaten effective conservation of marine turtles (Witherington \& Martin 2000, Pendoley 2005, Salmon 2006, Hamann et al. 2010, Kamrowski et al. 2014a). Following emergence from the nest, hatchling sea-finding is generally agreed to be the result of a directional preference for horizon lines that are low and bright (Daniel \& Smith 1947, Mrosovsky \& Carr 1967, Mrosovsky \& Shettleworth 1968, Mrosovsky 1972, Limpus \& Kamrowski 2013), and an aversion to darker, elevated horizon lines, or silhouettes (Limpus 1971, van Rhijn 1979, van Rhijn \& van Gorkum 1983, Witherington \& Bjorndal 1991a, Salmon et al. 1992, Witherington 1992). Thus, an artificially lit landward horizon at the nesting beach can disrupt sea-finding (Witherington \& Martin 2000, Salmon 2003), resulting in increased hatchling mortality (Lutcavage et al. 1997).

Both wavelength and intensity of lighting influence hatchling sea-finding (Witherington \& Bjorndal 1991b): hatchlings show a marked behavioural response to shorter wavelengths of light even when the longerwavelength light is emitted at heightened intensities (Mrosovsky \& Shettleworth 1968, Witherington \& 
Bjorndal 1991b, Witherington 1992). Based on such findings, efforts to mitigate lighting impacts at nesting beaches have generally focused on modifying or shielding light sources to make them less attractive to turtles (e.g. Bertolotti \& Salmon 2005, Sella et al. 2006).

Yet, intra- and inter-species differences in turtle response to different wavelengths of light exist. For example, loggerheads in Florida were shown to have an aversion to longer-wavelength light in the yellow part of the visible spectrum, which did not exist for green turtles tested in the same experiment (Witherington \& Bjorndal 1991b). However, a recent study using the same methodology demonstrated that Australian loggerhead hatchlings do not show the same aversion to yellow light (Fritsches 2012). These studies highlight the importance of population-specific research (e.g. Kamrowski et al. 2014b) to ensure lighting management is effective at different beaches impacted by lighting issues. Such findings also indicate that while modifying wavelength characteristics of light sources may be one useful management strategy to reduce impacts of light on marine turtles (e.g. Witherington \& Bjorndal 1991b), effective management of lighting is a complex task which will likely require multiple management strategies to be used in combination. Given that hatchlings use both brightness and horizon line elevation cues in seafinding, in coastal areas where lighting cannot be reduced, modifications to beach topography may be a useful tool to aid management (Tuxbury \& Salmon 2005, Limpus \& Kamrowski 2013), particularly since research suggests that when both cues are present, elevation functions as the dominant sea-finding cue (Salmon et al. 1992, Limpus \& Kamrowski 2013).

In coastal regions of Australia, globally important nesting aggregations of turtles (Limpus 2009) are currently threatened by human population expansion (Hennessy et al. 2007) and rapid industrialisation (Condie 2007, Greenpeace Australia 2012). The flatback turtle Natator depressus (Garman), which is endemic to the Australian continental shelf and is thought to nest solely on Australian beaches (Limpus et al. 1984, Parmenter \& Limpus 1995), is one of the least understood species of marine turtle (Sperling 2007, Limpus 2009). The flatback is the only turtle species listed as 'Data Deficient' by the IUCN (IUCN 2014); few published data exist for flatback hatchling response to wavelengths and intensities of light outside of laboratory conditions (Pendoley 2005, Fritsches 2012), or for their behavioural response during exposure to artificial lighting at the nesting beach (but see Limpus \& Kamrowski 2013, Kamrowski et al. 2014b); and additionally, of 4 distinct population management units of flatback turtles currently recognised (Limpus 2009), published information focused on Western Australian (WA) flatback turtles is scarce (Pendoley et al. 2014). Yet, nesting beaches used by flatback turtles in the North West Shelf of WA were recently found to be some of the most light-exposed nesting areas in Australia (Kamrowski et al. 2012, 2014a).

Furthermore, artificial lighting generated by industrial activities is recognised to be a major pressure on marine turtles in WA (Pendoley 2000, 2005, Environment Australia 2003, Department of Environment and Conservation 2007), and recent and future developments located in close proximity to turtle nesting beaches are expected to manage lighting to prevent luminaires being directly visible from the beach (i.e. by shielding lights, mounting lights low, etc.; Environmental Protection Agency 2010). However, industrial facilities often have numerous lights which create a conspicuous light glow visible over large distances despite shielding of individual light sources (authors' pers. obs.). Although glow from indirect sources of light have been shown to influence turtle behaviour (Salmon et al. 1995, Salmon 2006), few studies have assessed flatback hatchling response to light glow at the nesting beach (but see Pendoley 2005, Kamrowski et al. 2014b).

Consequently, studies assessing impacts of coastal and industrial light glow on flatback turtles are both crucial and timely. We present data from 2007 which investigated the orientation of flatback hatchlings at the nesting beach when exposed to light glow produced at 3 light intensities by 3 types of standard artificial light typically used in industrial settings (Pendoley 2005). The light sources were positioned either behind a high dune (producing a high, dark silhouette) or to the side in a low creek bed (producing a low silhouette and bright horizon line). Our overarching aims were twofold: (1) to provide population-specific information regarding flatback response to artificial lighting, and (2) to determine the value of changes in horizon elevation as a management strategy anywhere where artificial lighting disrupts hatchling sea-finding.

\section{MATERIALS AND METHODS}

\section{Study site}

The Barrow, Lowendal, Montebello (B-L-M) Island complex emerges from the North West Shelf of WA 
between $20^{\circ} 21^{\prime} \mathrm{S}$ and $20^{\circ} 57^{\prime} \mathrm{S}$, and $115^{\circ} 35^{\prime} \mathrm{E}$ and $115^{\circ} 18^{\prime} \mathrm{E}$ (Fig. 1). Barrow Island is the largest of 315 islands in the group, roughly 28600 hectares. It is a Class A nature reserve with no permanent residences, managed by the Western Australian Department of Parks and Wildlife. Barrow Island has been the site of an operating onshore oil field for the past $50 \mathrm{yr}$ and is currently also home to the Gorgon Project (liquified natural gas development). The present study was carried out 2 yr prior to commencement of construction on the Gorgon liquefied natural gas (LNG) plant.

All trials were conducted in February 2007 on Yacht Club Beach (Fig. 1), 1 of 6 important flatback nesting beaches on Barrow Island, chosen due to its remoteness from artificial light sources. The beach flat was approximately $10 \mathrm{~m}$ wide from the base of the dune to the high-tide line, and the supra-tidal zone was backed by vegetated dunes that were $10.7 \mathrm{~m}$ tall, with the beach grass Spinifex longifolius growing in a band at their base. A circular pitfall arena, $3 \mathrm{~m}$ in diameter with a $30 \mathrm{~cm}$ deep collection trench at the perimeter, was constructed midway between the hightide line and the vegetated dunes (Fig. 2). The arena was similar to that used in previous studies (e.g. Witherington \& Bjorndal 1991a, Kamel \& Mrosovsky 2005, Pendoley 2005) and based on the design first described by Mrosovsky (1972). The same arena was used for all trials, and was restored by sweeping the sand smooth between trials. The reference line at $0^{\circ}$ was along the most direct ray to the ocean.

\section{Hatchlings}

Flatback hatchlings were collected from Yacht Club Beach or the adjacent Terminal Beach (Fig. 1) on the same evening each trial was run. Hatchlings were only used if they had been collected after emerging naturally from the sand or if they were found with a flat plastron and within $10 \mathrm{~cm}$ of the sand surface. This ensured that poorly developed, less fit turtles or those still in the process of hatching were not used.

After collection, hatchlings were held in the dark in a black plastic crate at the test site for 2-4 $\mathrm{h}$ until needed. A minimum of 20 hatchlings were selected

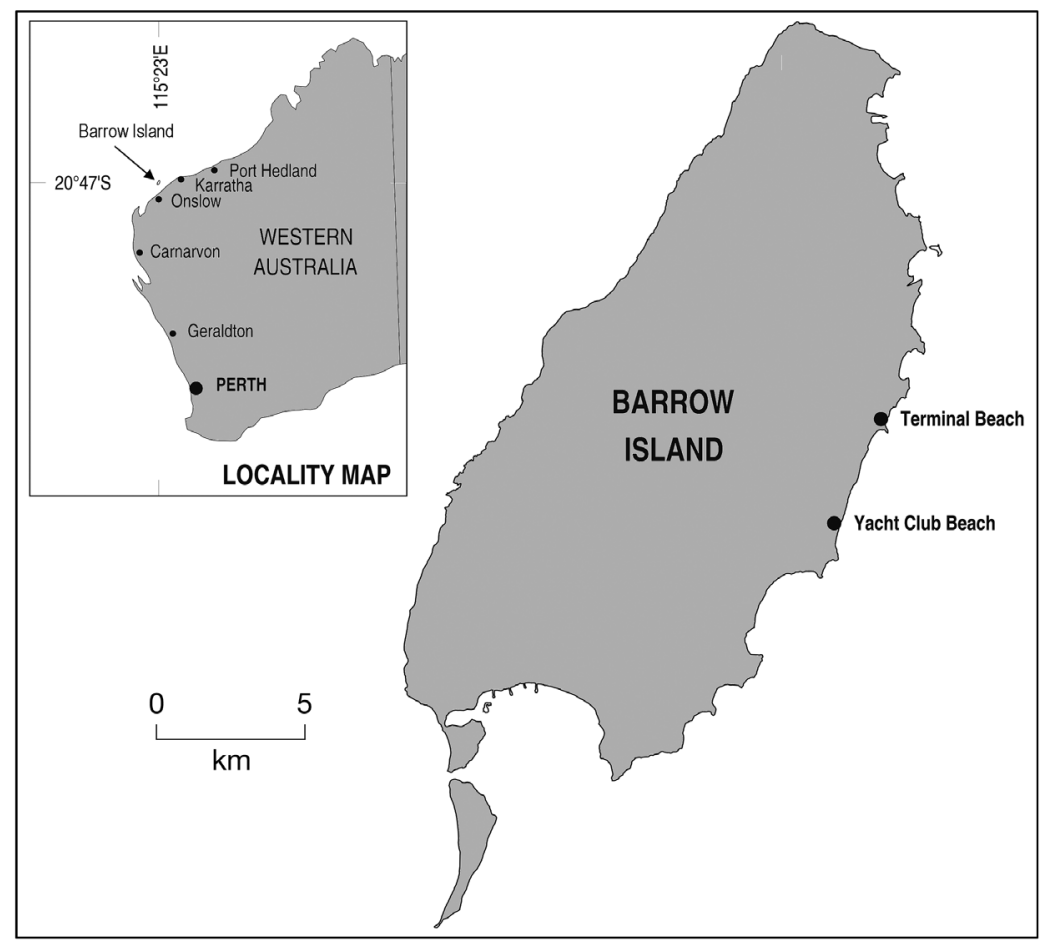

Fig. 1. Study location

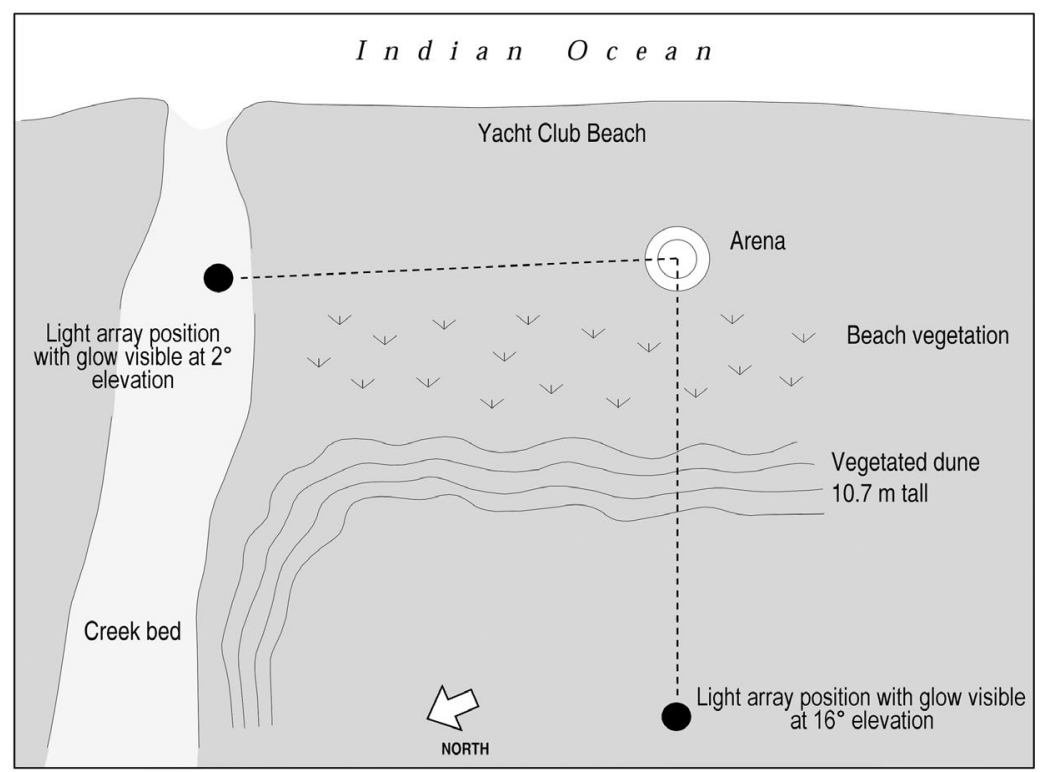

Fig. 2. Experimental setup on Yacht Club Beach (not to scale). The same arena was used in all trials, located $150 \mathrm{~m}$ from the light array. Expt 1: light array positioned behind a $10.7 \mathrm{~m}$ dune; Expt 2: light array positioned in a nearby shallow creek bed 
for each experimental trial, and were released in a group from a bag at the centre of the arena by a string controlled from outside the arena. The point where each hatchling track terminated at the collection trench was marked with a flag and the angle between the $0^{\circ}$ reference ray and that of the flag was measured using a laser-level mounted on a rotating base capable of discriminating $1^{\circ}$ increments. Hatchlings were allowed 2 min following release to reach the collection trench at the arena perimeter. Hatchlings that did not reach the arena perimeter in the allotted time were excluded from the data analysis. Hatchlings were only used once and then immediately released on a dark section of the test beach.

\section{Artificial light}

Trials occurred over 5 consecutive nights, from February 17-21, during the new moon period. The sky was dark and clear every night, with sparse clouds present only on the night of February 20. The artificial light sources were assembled on a metal frame in an array consisting of 3 types of bulbs: highpressure sodium vapour (HPS), metal halide (MH), and fluorescent white light (FW). Each light type has a very different standard spectral power curve (see Figs. S1-S3 in Supplement 1 at www.int-res.com/ articles/suppl/m529p279_supp.pdf). Within the visible spectrum, MH light is enriched in short wavelength light between $400-500 \mathrm{~nm}$ relative to FW and HPS, but emits light in wavelength peaks between 400 and $600 \mathrm{~nm}$. FW is dominated by a wavelength peak between $550-650 \mathrm{~nm}$, and spans $400-650 \mathrm{~nm}$, while HPS is characterised by a single peak spanning 560-600 nm, but in total spans 500-630 nm (Pendoley 2005, Elvidge et al. 2010). Total output for the different light sources was restricted to combinations of 250 and $400 \mathrm{~W}$ bulbs for MH and HPS, and multiples of $36 \mathrm{~W}$ bulbs for FW.

The light intensities we tested were $500 \mathrm{~W}$ (low intensity), $1000 \mathrm{~W}$ (medium intensity), and $1300 \mathrm{~W}$ (high intensity) for $\mathrm{MH}$ and HPS, while the closest approximation to these intensities was 504, 1008, and 1296 W, respectively, for FW. These intensities closely match lights (both types and wattages) which have been observed at industrial installations in WA located as close as $100 \mathrm{~m}$ to adjacent turtle nesting beaches (Pendoley 2005).

In Expt 1, the light array was positioned approximately $150 \mathrm{~m}$ from the arena, $180^{\circ}$ from the most direct route to the ocean, behind a $10.7 \mathrm{~m}$ tall vegetated sand dune (Fig. 2) such that the glow was visi- ble above the dune at an elevation of $16^{\circ}$ from the arena on the beach flat. In the second experiment, the same light array was set up approximately $150 \mathrm{~m}$ from the arena in a shallow creek bed at $95^{\circ}$ from the most direct route to the ocean. A band of low vegetated sand mounds along the creek edge was between the arena and the light source such that the glow from the light array was visible at $2^{\circ}$ elevation from the arena on the beach flat (Fig. 2). The angle of elevation was manually calculated using the distance from the arena centre to the highest point immediately in front of the light array, and the height of the beach in front of the light array. These elevations were confirmed the following year using a laser inclinometer (Leica Geosystems). The light array itself (i.e. the frame/bulbs) was not visible in either experiment from the arena site, as viewed by researchers lying prone at beach level; only the glow was visible. The light array was powered by a $5 \mathrm{kVa}$ 'silent' running diesel generator placed a further $25 \mathrm{~m}$ from the arena. Control trials without artificial light were also run.

\section{Data analysis}

Data were analysed manually and using the statistical software program Oriana 3 for Windows. The orientation recorded for each hatchling track was used to determine the direction of the mean vector $(\mu)$, its $95 \% \mathrm{CI}$, the length of the mean vector $(\mathrm{r})$, and the circular standard deviation (circular SD) for each treatment group. The value of $\mathrm{r}$ indicates the strength of the orientation; $r=0$ if the individual track vectors are spread evenly around the circle, and $\mathrm{r}=1$ if all individual track vectors are oriented in the same direction. For both control and experimental trials, Rayleigh tests were used to calculate a probability that the data were randomly distributed. That hypothesis was rejected when $\mathrm{p}<0.05$. For the treatment trials, hatchlings were considered either 'sea-finding' or 'misoriented'. We considered hatchlings to be 'seafinding' if they were significantly oriented and the $95 \%$ CI of the mean bearing fell within 1 circular SD of the control mean. We considered hatchlings to be 'misoriented' if they had a significant orientation but the $95 \%$ CI of the mean bearing did not fall within 1 circular SD value of the control mean. Comparisons were also made between hatchling orientation in the 2 experiments (1: 'lights behind dune' versus 2: 'lights in creek bed') under the 3 different light intensities, for each light type, using Watson's $U^{2}$ tests (Mardia \& Jupp 2000). 
Data for each of the 2 experiments were also analysed using a variant of the Rayleigh test (Mardia \& Jupp 2000), following methods described in Limpus \& Kamrowski (2013). In each experiment, data were pooled across light type and intensity, and Eqs. (1) and (2) used to determine if hatchling travel direction was uniformly distributed or whether hatchlings travelled in a preferred, specific direction (i.e. towards the ocean, $m_{1}$, or towards the light array, $m_{2}$ ). If model $m$ is true, then $\bar{C}^{(m)}$ should be near 1 ; if it is false, then $\bar{C}^{(m)}$ should be closer to 0 . However, if $\bar{C}^{(m)}$ is closer to -1 , it suggests the model is 'anti-true', i.e. in the opposite direction. The results of this analysis are reported in the format $(T(\bar{C}, \mathrm{n}))$. T indicates the test statistic used to determine if model $m$ is significantly different to a uniform distribution.

$$
\begin{gathered}
\bar{C}^{(m)}=\left(\frac{1}{\mathrm{n}}\right) \sum_{j=1}^{n} \cos \left(\theta_{j}-\phi_{j}{ }^{(m)}\right) \\
T^{(m)}=(2 \mathrm{n})^{1 / 2} \bar{C} \sim N(0,1)
\end{gathered}
$$

where: $\mathrm{n}=$ sample size; $\theta_{j}=$ the mean hatchling bearing for $j$ th experimental trial, $j=1, \ldots, \mathrm{n}_{i} m=$ model describing the expected $\theta_{j}$ if hatchlings orient towards a particular cue $\left(m_{1}=\right.$ direct route to ocean, $m_{2}=$ direct route to light array); $\phi_{j}^{(m)}=$ the hypothesised average angle for the $j$ th group under the $m$ th model; and critical values of $N(0,1)$ were obtained from Mardia \& Jupp (2000).

\section{RESULTS}

In total, 595 flatback hatchlings were used. Fourteen hatchlings failed to leave the arena within 2 min and were thus removed from further analysis. Control trials without artificial lights were run on 3 days $(\mathrm{n}=23,30$, and 18 hatchlings per trial), and hatchlings were found to be significantly oriented (Rayleigh test: $Z=$ 65.5, $\mathrm{p}<0.001)$. The mean orientation vector $(\mu)$ was $358.1^{\circ} \pm 16.3$ (circular $\mathrm{SD}$ ), and the r-vector was 0.96 (Figs. 3 $\& 4)$. Thus, for the experimental trials, a 'sea-finding' outcome was considered to have occurred when $r$ was close to 1 , and $95 \%$ CI of $\mu$ overlapped the range of the circular SD for the control, i.e. between $341.8^{\circ}$ and $14.4^{\circ}$. A 'misorientation' outcome was considered to have occurred when $r$ was close to 1 and hatchlings were significantly oriented, but $95 \%$ CI of $\mu$ were outside the range of $341.8^{\circ}$ and $14.4^{\circ}$ (Figs. $3 \& 4$ )
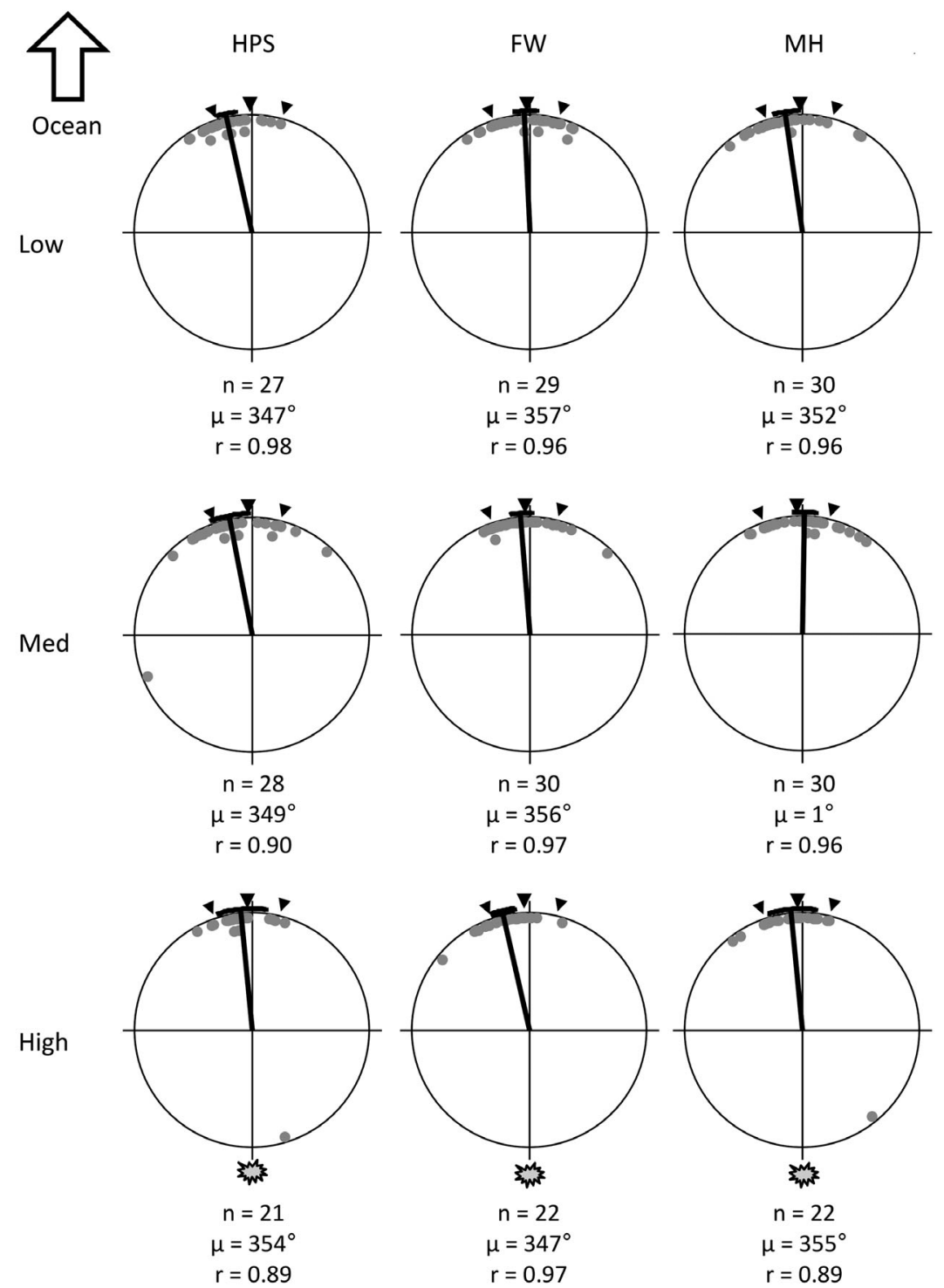

Fig. 3. Expt 1. Flatback hatchling orientation in response to different light types (HPS: high-pressure sodium vapour; FW: fluorescent white; $\mathrm{MH}$ : metal halide) and intensities (low, medium, high) when the light array was positioned $150 \mathrm{~m}$ distant behind a $10.7 \mathrm{~m}$ high dune (direction denoted by $\mathrm{m}^{\mathbf{3}}$ ), producing a silhouette of $16^{\circ}$ elevation. Each grey dot represents 1 hatchling exit point; the straight black line and $\mu$ denote mean hatchling bearing. Curved black line shows $95 \%$ CI for the mean. Black triangles outside each circle represent the mean (centre) hatchling bearing and 1 circular SD (left and right) obtained during control trials. $\mathrm{r}$ : length of the mean vector 

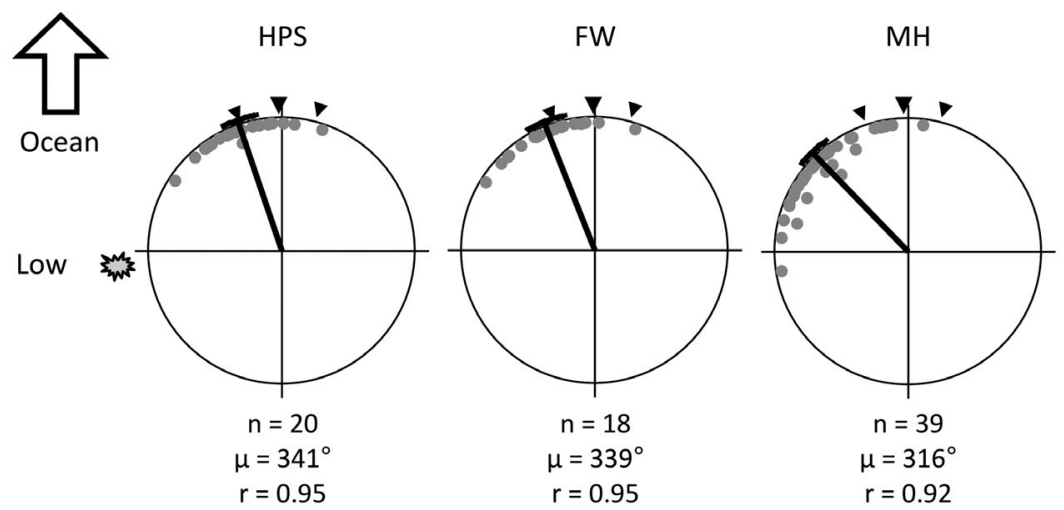

Med
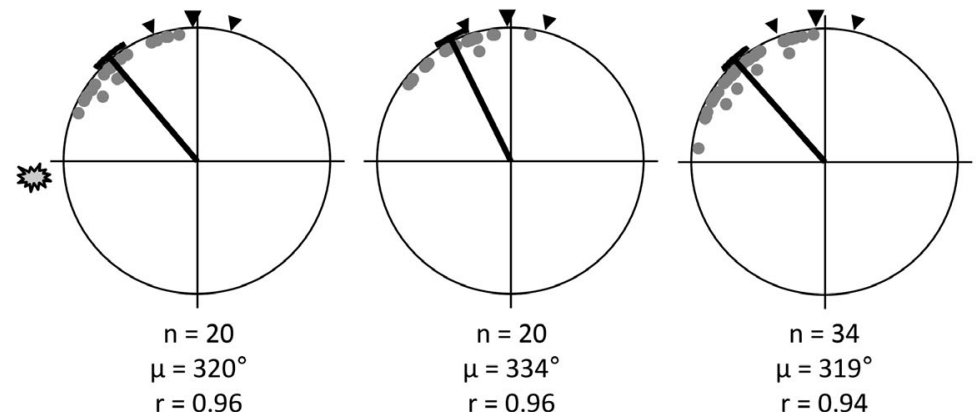

High
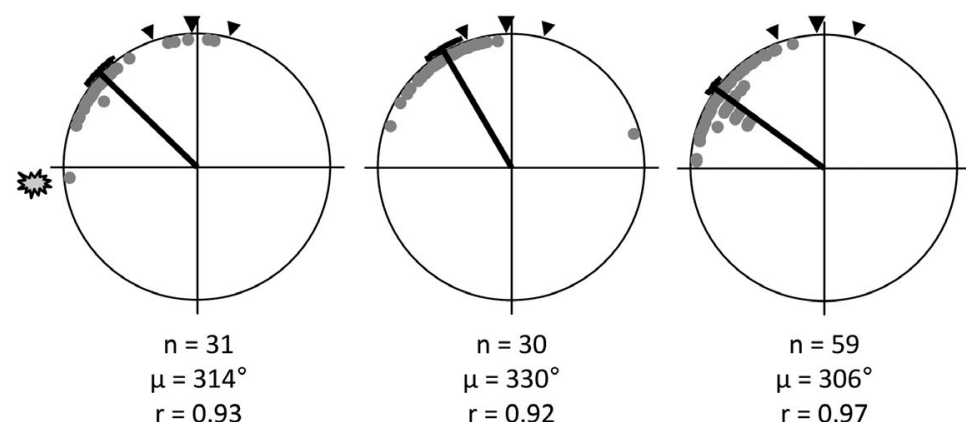

Fig. 4. Expt 2. As in Fig. 3, but with light array positioned $150 \mathrm{~m}$ distant in a shallow creek bed, producing a silhouette of $2^{\circ}$ elevation deviation of the distribution in response to low-intensity HPS and FW light fell within the $95 \%$ CI of the control trials i.e. a 'sea-finding' response (Fig. 4; Table S2 in Supplement 2 at www.int-res.com/articles/suppl/m529 p279_supp.pdf).

Similarly, statistical comparisons between trials in Expts 1 and 2 (Table 1) indicated significant differences in hatchling orientation at medium and high intensities of all 3 light types, and also at low light intensities of the $\mathrm{MH}$ light. At low intensities of FW and HPS lights, there was no significant difference in orientation between hatchlings in Expt 1 (light behind dune) compared to Expt 2 (light in creek bed).

The Rayleigh test variant confirmed that hatchlings exposed to light behind the high dune (Expt 1) exhibited seemingly unaffected sea-finding behaviour. Hatchlings were significantly oriented towards the ocean $(T(0.99,9)$ $=4.2, \mathrm{p}<0.05)$, and were significantly oriented directly away from the light array behind the dune (the 'anti-true' direction) $(T(-0.99,9)=-4.2, \mathrm{p}<0.05)$. In contrast, hatchlings exposed to light from the creek bed at a much lower angle of elevation (Expt 2), although found to be significantly oriented towards the ocean $(T(0.8,9)=3.4, \mathrm{p}<$ $0.05)$, were also found to be significantly oriented towards the light array $(T(0.5,9)=2.1, \mathrm{p}<0.05)$.
When the artificial light array was illuminated and situated behind the dune, producing light glow above the dune silhouette at $16^{\circ}$ elevation, hatchlings were significantly oriented (Rayleigh test: $p<0.001$ ) and tracks consistently ended in a 'sea-finding' outcome, regardless of the presence of light type and/or light intensity (Fig. 3; Table S1 in Supplement 2 at www. int-res.com/articles/suppl/m529p279_supp.pdf).

When the light array was in the creek bed (behind a $2^{\circ}$ horizon), hatchlings continued to show significant orientation (Rayleigh test: $\mathrm{p}<0.001$ ). However, their mean dispersion angles in all experiments were displaced to the left of the most direct route to the ocean. Hatchlings were 'misoriented' at the medium and high intensities of all light types, and at the low intensity of the $\mathrm{MH}$ light. In contrast, the leftward
Table 1. Comparisons between mean hatchling bearing in Expt 1 (lights behind elevated dune) and Expt 2 (lights in shallow creek bed), for each combination of light intensity and light type, using Watson's $U^{2}$ tests (Mardia \& Jupp 2000). Significant differences are in bold

\begin{tabular}{|lcl}
\hline Light type & Intensity & $\begin{array}{l}\text { Comparison between } \\
\text { Expts } 1 \text { and } 2\end{array}$ \\
& & \\
\hline High-pressure & Low & $U^{2}(20,27)=0.073, \mathbf{p}>0.05$ \\
sodium & Med & $\boldsymbol{U}^{2}(\mathbf{2 0}, \mathbf{2 8})=\mathbf{0 . 3 9 6}, \mathbf{p}<\mathbf{0 . 0 0 1}$ \\
& High & $\boldsymbol{U}^{2}(\mathbf{2 1}, \mathbf{3 1})=\mathbf{0 . 7 0 2}, \mathbf{p}<\mathbf{0 . 0 0 1}$ \\
Fluorescent & Low & $U^{2}(18,29)=0.178, \mathbf{p}>0.05$ \\
white & Med & $\boldsymbol{U}^{2}(\mathbf{2 0}, \mathbf{3 0})=\mathbf{0 . 2 7 6}, \mathbf{p}<\mathbf{0 . 0 1}$ \\
& High & $\boldsymbol{U}^{2}(\mathbf{2 2}, \mathbf{3 0})=\mathbf{0 . 2 8}, \mathbf{p}<\mathbf{0 . 0 1}$ \\
Metal & Low & $\boldsymbol{U}^{2}(\mathbf{3 0}, \mathbf{3 9})=\mathbf{0 . 7 7 8}, \mathbf{p}<\mathbf{0 . 0 0 1}$ \\
halide & Med & $\boldsymbol{U}^{2}(\mathbf{3 0}, \mathbf{3 4})=\mathbf{0 . 5 9}, \mathbf{p}<\mathbf{0 . 0 0 1}$ \\
& High & $\boldsymbol{U}^{2}(\mathbf{2 2}, \mathbf{5 9})=\mathbf{1 . 1 4}, \mathbf{p}<\mathbf{0 . 0 0 1}$ \\
& & \\
\hline
\end{tabular}




\section{DISCUSSION}

This study focused on the importance of an elevated dark horizon for sea-finding in flatback hatchlings exposed to light glow produced by standard industrial light sources, at distances and intensities present at nesting beaches in WA (Pendoley 2005). We found that flatback hatchlings released on the dark beach in the absence of artificial lighting consistently oriented directly towards the ocean and away from the high dark dune behind. The sea-finding ability of hatchlings exposed to artificial light glow visible behind a high dune (at $16^{\circ}$ elevation from the beach flat), which produced a high, dark silhouette, was not disrupted; however, hatchlings exposed to light glow visible at a low elevation from the beach flat $\left(2^{\circ}\right)$ displayed reduced sea-finding ability. Our findings thus support previous research which found horizon cues to be more influential than brightness cues for guiding hatchling sea-finding (Limpus 1971, Salmon et al. 1992). Our results also provide support for the proposition that hatchlings primarily respond to horizons that are low and bright, rather than simply orienting away from an elevated horizon (Limpus \& Kamrowski 2013), since, when the light was positioned at $95^{\circ}$ from the arena, hatchling travel direction shifted around towards the low, bright horizon (the glow from the light array), and away from the most direct route to the ocean, rather than remaining directly away from the elevated dune behind the arena.

Hatchling response to glow resulting from medium to high light intensities of $1000 \mathrm{~W}$ and above did not significantly differ between the 3 different types of standard lighting (HPS, MH, and FW) in either experiment. In Expt 1 (light behind elevated dune), hatchlings remained ocean-oriented in all trials (Fig. 3), whereas in Expt 2 (light in shallow creek bed), all types of light reduced the sea-finding ability of hatchlings (Fig. 4). However, at the lower intensity $(500 \mathrm{~W})$, light from HPS and FW lights did not significantly interfere with hatchling sea-finding behaviour, whilst $\mathrm{MH}$ light remained disruptive. Flatback hatchlings in laboratory studies have been found to preferentially respond to shorter wavelengths of visible light (Pendoley 2005, Fritsches 2012), thus this finding can be explained by the spectral characteristics of HPS, FW, and MH light (Pendoley 2005, Elvidge et al. 2010): $\mathrm{MH}$ emits more shortwavelength light between $390-500 \mathrm{~nm}$ relative to FW and HPS (Figs. S1-S3 in Supplement 1 at www. int-res.com/articles/suppl/m529p279_supp.pdf).

This finding also suggests that hatchlings were sensitive to all tested intensities of $\mathrm{MH}$ light at a dis- tance of $150 \mathrm{~m}$, whereas hatchling sensitivity to HPS and FW lighting located $150 \mathrm{~m}$ distant appears to originate at an intensity between 500 and $1000 \mathrm{~W}$. This information can be used to refine future studies, and we suggest that future research investigates multiple species' hatchling sensitivity to light glow from standard light sources under a greater range of light intensities.

Recent research has demonstrated that although longer-wavelength 'turtle-friendly' lights are less disruptive than standard light sources, some hatchling sea-finding remained disrupted in the presence of such light (Sella et al. 2006, Robertson 2013). Consequently, until lighting can be developed which causes zero disruption to hatchling sea-finding behaviour, we suggest that at flatback nesting beaches where standard lighting types are deemed necessary, low intensities of HPS or FW lighting should be used in preference to higher intensities of these lights, or to $\mathrm{MH}$ lights of any intensity.

Overall, our findings imply that the degree of disruption that artificial light glow poses to hatchling sea-finding is highly dependent upon beach topography and horizon elevation (see also Kamrowski et al. 2014b). Consequently, we support the view that modifying beach profile at sites where hatchlings show disruption from artificial light may be a valuable strategy for management purposes (Tuxbury \& Salmon 2005, Limpus \& Kamrowski 2013). This is of particular importance at nesting beaches in Australia at present, since rapid industrialisation and coastal development are likely to significantly alter the light horizons of numerous marine turtle nesting beaches (Condie 2007, Greenpeace Australia 2012, Kamrowski et al. 2012, 2014a).

We are not, however, advocating that altering beach topography should be used instead of managing and reducing artificial light levels. Further research is necessary to fully understand the potential management benefit of modifying beach topography to reduce lighting impacts. For example, it is not currently clear how high a silhouette must be before it functions as a cue to guide hatchlings away. In addition, as observer distance from an elevated beach area increases, the lower the perceived angle of elevation will become; thus lights which may be obscured by dunes close to the beach may become visible to hatchlings emerging from nests at greater distances along the beach or to hatchlings swimming away from the beach during the offshore migration. Since swimming hatchlings may orient towards light cues in the absence of wave cues (e.g. Lorne \& Salmon 2007, Harewood \& Horrocks 2008), onshore 
lights 'appearing' as hatchlings travel further from shore could potentially cause them to head back inland until the lights are once again obscured (see Limpus \& Reed 1985 for a similar observation of disoriented adult turtles on land). An increased time spent swimming in near-shore waters would likely increase hatchling predation risk (Gyuris 1994, Stewart \& Wyneken 2004, Whelan \& Wyneken 2007), as well as use up stored energy hatchlings require to swim quickly out of predator-rich, shallow coastal areas (Hamann et al. 2007, Booth \& Evans 2011, Pereira et al. 2012). Hatchling mortality at sea is much less visible to managers than that occurring on land. Thus, while beach profile modifications may be useful in combination with efforts to reduce light and technical modifications to light sources, it is critical that beach profile modifications are not used as the sole management measure where nesting beaches are exposed to artificial lighting. Further research which assesses the potential modifying influence of horizon elevation on artificial lighting impacts for swimming hatchlings would also be highly valuable.

Furthermore, it must be borne in mind that flatback hatchlings were previously found to be less sensitive to short-wavelength light compared to hatchlings of green and hawksbill turtles (Pendoley 2005). Both of these latter species occasionally nest on beaches dominated by breeding flatback turtles in WA (K. Pendoley pers. obs.), and would thus likely show greater disruption to the types of light glow produced by the light array employed in this study than we observed with the flatback hatchlings. Future work is necessary to expand on our study and test hatchlings of other species to light glow from standard industrial light sources behind different horizon elevations, under natural conditions.

We did not independently measure the visible intensity of the light array from the arena site, nor did we measure the brightness of each direction from the arena (as has been done in previous studies, e.g. Bertolotti \& Salmon 2005, Kamrowski et al. 2014b). However, we do not believe this would have significantly affected our findings or the conclusions we have drawn. At the time of data collection, there were no standardised methods for measuring light emissions and glow (Narisada \& Schreuder 2004). Recognition of this fact subsequently led to the development of a novel method for measuring light close to turtle nesting beaches, and future hatchling orientation work around the world will benefit from measurements of sky glow and light emissions using modified astronomical cameras (Pendoley Environmental 2011, Pendoley et al. 2012). Instead, in the present study, we chose to measure hatchling behavioural response to standard light sources, of known intensities, which currently exist close to nesting beaches in WA (Pendoley 2005).

In addition, we used the same beach location in each experiment to control for potential differences in brightness as a result of possible variations in substrate characteristics between sites affecting sand reflectance qualities (Emslie 1966, Aronson et al. 1967). Keeping the arena in the same location for both experiments meant that in order to change the elevation at which the glow was visible, it was necessary to position the light array at different bearings from the centre of the arena in each experiment. However, we do not consider that the 'direction' of the light source would have affected our findings or conclusions, because hatchlings do not respond to 'direction' per se. The direction in which hatchlings must crawl to reach the ocean is not innate knowledge; e.g. hatchlings from nests translocated from the eastern coast of Costa Rica to the west coast immediately crawled westward towards the ocean upon emergence in the new location despite the fact that such a heading would have led inland from the original nest site (Carr \& Ogren 1960). Moreover, previous arena studies have shown that hatchlings tested in the same arena over multiple trials will change their direction of travel in response to different brightness or elevation cues (Mrosovsky \& Shettleworth 1968, Mrosovsky 1970, Limpus \& Kamrowski 2013), i.e. the direction a hatchling chooses is dependent upon the environmental cues present at that time, not the 'direction' itself. Yet in our study, when the light array was positioned in the creek bed at $95^{\circ}$ from the shortest route to the ocean, the prevailing environmental cues influenced hatchlings so that although they were significantly oriented towards the light array, they also remained significantly oriented towards the ocean. Future work would therefore benefit from selection of a site, if possible, where the landward horizon topography differed enough so that that light array could be positioned at equal bearings from the most direct ocean bearing, but behind beach topographical features of different heights.

\section{CONCLUSIONS}

Our study adds to limited published data focused on orientation of flatback turtle hatchlings. We have demonstrated that flatback hatchlings are able to see and respond to sky glow produced by standard light 
sources used in industry, namely high-pressure sodium vapour, metal halide, and fluorescent white lights, at intensities ranging from 500 to $1300 \mathrm{~W}$ over a distance of $150 \mathrm{~m}$.

We also found that the sea-finding ability of flatback hatchlings exposed to light glow visible at $2^{\circ}$ elevation from the beach flat was significantly reduced compared to hatchlings exposed to light glow at $16^{\circ}$ elevation. All species of marine turtle have highly similar sea-finding behaviour as hatchlings. We thus recommend that in areas where artificial lighting is deemed necessary close to turtle nesting beaches, beach profile alteration should be considered as a management measure together with other management measures, including light-reduction strategies and modifications to light sources. As coastal development continues to encroach on nesting beaches worldwide, this combination of management tools will help to provide the greatest possible protection of breeding turtles.

Acknowledgements. Chevron Australia and the Gorgon Project provided logistical support. Jarrad Sherborne, Anna Vitenbergs, Rowan Murless, Luke Wheat, Paul Tod and Dorian Moro assisted with the field work. Professor John Kent, University of Leeds, provided advice on the use of circular statistics. Early drafts of this manuscript benefitted from the comments of Tony Tucker, Milani Chaloupka, and Nicholas Pilcher. This assistance is gratefully acknowledged. This research was authorised by a Western Australian Department of Conservation and Land Management (CALM) license to take fauna for scientific purposes (SF005670), and the necessary permit to enter CALM land (CE001551).

\section{LITERATURE CITED}

Aronson JR, Emslie AG, Allen RV, McLinden HG (1967) Studies of the middle- and far-infrared spectra of mineral surfaces for application in remote compositional mapping of the Moon and planets. J Geophys Res 72:687-703

Bertolotti L, Salmon M (2005) Do embedded roadway lights protect sea turtles? Environ Manage 36:702-710

Booth DT, Evans A (2011) Warm water and cool nests are best. How global warming might influence hatchling green turtle swimming performance. PLoS ONE 6: e23162

Carr A, Ogren L (1960) The ecology and migrations of sea turtles. 4. The green turtle in the Caribbean Sea. Bull Am Mus Nat Hist 121:7-48

Condie S (2007) North West Shelf joint environmental management study final report. Commonwealth Scientific and Industrial Research Organisation (CSIRO) and the Western Australian Government. www.cmar.csiro.au/ nwsjems/reports.htm

Daniel RS, Smith KU (1947) The sea-approach behavior of the neonate loggerhead turtle, Caretta caretta. J Comp Physiol Psychol 40:413-420

Department of Environment and Conservation (2007) Management plan for the Montebello/Barrow Islands marine conservation reserves. 2007-2017. Department of Environment and Conservation, Perth

Elvidge CD, Keith DM, Tuttle BT, Baugh KE (2010) Spectral identification of lighting type and character. Sensors (Basel) 10:3961-3988

Emslie A (1966) Theory of diffuse spectral reflectance of a thick layer of absorbing and scattering particles. In: Heller GB (ed) Thermophysics and temperature control of spacecraft and entry vehicles. Progress in astronautics and aeronautics, Vol 18. Academic Press, New York, NY, p 281-290

Environment Australia (2003) Recovery plan for marine turtles in Australia. Environment Australia Marine Species Section, Canberra

Environmental Protection Agency (2010) No. 5: Environmental assessment guideline for protecting marine turtles from light impacts. Environmental Protection Agency, Perth

Fritsches KA (2012) Australian loggerhead sea turtle hatchlings do not avoid yellow. Mar Freshw Behav Physiol 45: 79-89

Greenpeace Australia (2012) Boom goes the reef: Australia's coal export boom and the industrialization of the Great Barrier Reef. Greenpeace Australia Pacific, Sydney

$>$ Gyuris E (1994) The rate of predation by fishes on hatchlings of the green turtle (Chelonia mydas). Coral Reefs 13: $137-144$

> Hamann M, Jessop TS, Schäuble CS (2007) Fuel use and corticosterone dynamics in hatchling green sea turtles (Chelonia mydas) during natal dispersal. J Exp Mar Biol Ecol 353:13-21

Hamann M, Godfrey MH, Seminoff JA, Arthur K and others (2010) Global research priorities for sea turtles: informing management and conservation in the 21 st century. Endang Species Res 11:245-269

Harewood A, Horrocks J (2008) Impacts of coastal development on hawksbill hatchling survival and swimming success during the initial offshore migration. Biol Conserv 141:394-401

Hennessy K, Fitzharris B, Bates BC, Harvey N and others (2007) Australia and New Zealand. In: Parry ML, Canziani OF, Palutikof JP, van der Linden PJ, Hanson CE (eds) Climate change 2007: impacts, adaptation and vulnerability. Contribution of Working Group II to the Fourth Assessment Report of the Intergovernmental Panel on Climate Change. Cambridge University Press, Cambridge, p 507-540

IUCN (2014) Natator depressus. In: IUCN Red List of Threatened Species, Version 2014.3. www.iucnredlist. org (accessed 10 March 2015)

Kamel SJ, Mrosovsky N (2005) Repeatability of nesting preferences in the hawksbill sea turtle, Eretmochelys imbricata, and their fitness consequences. Anim Behav 70: 819-828

> Kamrowski RL, Limpus C, Moloney J, Hamann M (2012) Coastal light pollution and marine turtles: assessing the magnitude of the problem. Endang Species Res 19:85-98

Kamrowski RL, Limpus C, Jones R, Anderson S, Hamann M (2014a) Temporal changes in artificial light exposure of marine turtle nesting areas. Global Change Biol 20: 2437-2449

Kamrowski RL, Limpus C, Pendoley K, Hamann M (2014b) Influence of industrial light pollution on the sea-finding behaviour of flatback turtle hatchlings. Wildl Res 41: 421-434 
Limpus C (1971) Sea turtle ocean finding behaviour. Search $2: 385-387$

Limpus C (2009) A biological review of Australian marine turtles. Environmental Protection Agency, Queensland Government, Brisbane

Limpus CJ, Kamrowski RL (2013) Ocean-finding in marine turtles: the importance of low horizon elevation as an orientation cue. Behaviour 150:863-893

Limpus C, Reed P (1985) Green sea turtles stranded by Cyclone Kathy on the south-western coast of the Gulf of Carpentaria. Wildl Res 12:523-533

Limpus C, Fleay A, Baker V (1984) The flatback turtle, Chelonia depressa, in Queensland: reproductive periodicity, philopatry and recruitment. Wildl Res 11:579-587

Lorne JK, Salmon M (2007) Effects of exposure to artificial lighting on orientation of hatchling sea turtles on the beach and in the ocean. Endang Species Res 3: 23-30

Lutcavage ME, Plotkin P, Witherington B, Lutz PL (1997) Human impacts on sea turtle survival. In: Lutz PL, Musick JA (eds) The biology of sea turtles. CRC Press, Boca Raton, FL, p 387-409

Mardia KV, Jupp PE (2000) Directional statistics, Vol 28. John Wiley \& Sons, Chichester

> Mrosovsky N (1970) The influence of the sun's position and elevated cues on the orientation of hatchling sea turtles. Anim Behav 18:648-651

> Mrosovsky N (1972) The water-finding ability of sea turtles. Brain Behav Evol 5:202-225

> Mrosovsky N, Carr A (1967) Preference for light of short wavelengths in hatchling green sea turtles, Chelonia mydas, tested in their natural nesting beaches. Behaviour 28:217-231

Mrosovsky N, Shettleworth SJ (1968) Wavelength preferences and brightness cues in the water finding behaviour of sea turtles. Behaviour 32:211-257

Narisada K, Schreuder D (2004) Light pollution handbook. Springer, Dordrecht

Parmenter CJ, Limpus CJ (1995) Female recruitment, reproductive longevity and inferred hatchling survivorship for the flatback turtle (Natator depressus) at a major eastern Australian rookery. Copeia 1995:474-477

Pendoley K (2000) The influence of gas flares on the orientation of green turtle hatchlings at Trevenard Island, Western Australia. In: Pilcher N, Ismail G(eds) Sea turtles of the Indo-Pacific: research management and conservation. ASEAN Academic Press, London, p 130-142

Pendoley K (2005) Sea turtles and the environmental management of industrial activities in north west Western Australia. Murdoch University, Perth

Pendoley K, Verveer A, Kahlon A, Savage J, Ryan RT (2012) A novel technique for monitoring light pollution. International Conference on Health Safety and Environment in Oil and Gas Exploration and Production. Society of Petroleum Engineers, Perth, www.onepetro.org/conferencepaper/SPE-158034-MS

Pendoley K, Bell CD, McCracken R, Ball KR and others (2014) Reproductive biology of the flatback turtle Natator depressus in Western Australia. Endang Species Res 23: 115-123

Pendoley Environmental (2011) Gladstone baseline sky cam light monitoring 2011. Prepared for Gladstone Ports Corporation. www.westernbasinportdevelopment.com.au/
media/pdf/Gladstone \% 20Baseline \% 20Sky \% 20Cam \% 20 Light\%20monitoring\%202011.pdf (accessed May 2013)

Pereira CM, Booth DT, Limpus CJ (2012) Swimming performance and metabolic rate of flatback Natator depressus and loggerhead Caretta caretta sea turtle hatchlings during the swimming frenzy. Endang Species Res 17: 43-51

Robertson K (2013) An assessment of 'turtle friendly' lights on the sea finding behaviour of loggerhead sea turtles (Caretta caretta) at Mon Repos, Queensland. School of Biological Sciences, University of Queensland, Brisbane

Salmon M (2003) Artificial night lighting and sea turtles. Biologist 50:163-168

Salmon M (2006) Protecting sea turtles from artificial night lighting at Florida's oceanic beaches. In: Rich C, Longcore $\mathrm{T}$ (eds) Ecological consequences of artificial night lighting. Island Press, Washington, DC, p 141-168

Salmon M, Wyneken J, Fritz E, Lucas M (1992) Seafinding by hatchling sea turtles: role of brightness, silhouette and beach slope as orientation cues. Behaviour 122:56-77

Salmon M, Tolbert MG, Painter DP, Goff M, Reiners R (1995) Behavior of loggerhead sea turtles on an urban beach. II. Hatchling orientation. J Herpetol 29:568-576

Sella KN, Salmon M, Witherington BE (2006) Filtered streetlights attract hatchling marine turtles. Chelonian Conserv Biol 5:255-261

Sperling J (2007) The behaviour and physiology of the gravid flatback turtle (Natator depressus). University of Queensland, Brisbane

Stewart K, Wyneken J (2004) Predation risk to loggerhead hatchlings at a high-density nesting beach in southeast Florida. Bull Mar Sci 74:325-335

> Tuxbury SM, Salmon M (2005) Competitive interactions between artificial lighting and natural cues during seafinding by hatchling marine turtles. Biol Conserv 121:311-316

van Rhijn FA (1979) Optic orientation in hatchlings of the sea turtle, Chelonia mydas. 1. Brightness: not the only optic cue in sea-finding orientation. Mar Behav Physiol 6: 105-121

van Rhijn FA, van Gorkum JC (1983) Optic orientation in hatchlings of the sea turtle Chelonia mydas. III. Sea-finding behavior: the role of photic and visual orientation in animals walking on the spot under laboratory conditions. Mar Behav Physiol 9:211-228

> Whelan CL, Wyneken J (2007) Estimating predation levels and site-specific survival of hatchling loggerhead sea turtles (Caretta caretta) from south Florida beaches. Copeia 2007:745-754

Witherington B (1992) Sea-finding behavior and the use of photic orientation cues by hatchling sea turtles. University of Florida, Gainesville

Witherington B, Bjorndal K (1991a) Influences of artificial lighting on the seaward orientation of hatchling loggerhead turtles Caretta caretta. Biol Conserv 55:139-149

> Witherington B, Bjorndal K (1991b) Influences of wavelength and intensity on hatchling sea turtle phototaxis: implications for sea-finding behavior. Copeia 1991: 1060-1069

Witherington B, Martin RE (2000) Understanding, assessing, and resolving light-pollution problems on sea turtle nesting beaches, 2nd edn (rev.). Tech Rep TR-2. Florida Fish and Wildlife Conservation Commission, Marine Research Institute, St. Petersburg

Submitted: January 5, 2015; Accepted: April 7, 2015

Proofs received from author(s): May 25, 2015 